\title{
Expressão gênica induzida por estresses abióticos em nódulos de feijão-caupi
}

\author{
Helder Anderson Pinto da Silva(1), Péricles de Souza Galisa(2), Roselaine Sanches da Silva Oliveira(2), \\ Marcia Soares Vidal(3) e Jean Luiz Simões-Araújo(3)
}

\begin{abstract}
(1)Universidade Federal do Rio de Janeiro, Campus da Ilha do Fundão, CEP 21941-590 Rio de Janeiro, RJ. E-mail: helderanderson@ufrj.br (2)Universidade Federal Rural do Rio de Janeiro, BR 465, Km 7, CEP 23890-000 Seropédica, RJ. E-mail: periclesgalisa@yahoo.com.br, roselainesanchez@yahoo.com.br ${ }^{(3)}$ Embrapa Agrobiologia, BR 465, Km 7, CEP 23890-000 Seropédica, RJ. E-mail: marcia@cnpab.embrapa.br, jean@cnpab.embrapa.br
\end{abstract}

Resumo - O objetivo deste trabalho foi avaliar o efeito isolado ou simultâneo dos estresses hídrico e térmico na expressão gênica em nódulos de feijão-caupi. A bactéria Bradyrhizobium japonicum (estirpe BR 3267) foi inoculada em sementes de feijão-caupi da cultivar IPA 206 e, 35 dias após a germinação, as plantas foram submetidas a diferentes regimes de disponibilidade hídrica e a estresse térmico, em casa de vegetação. Para a identificação dos genes diferencialmente expressos, foi utilizada a técnica de cDNA-AFLP, tendo-se isolado 67 fragmentos derivados de transcritos (FDTs) diferencialmente expressos. Após o sequenciamento dos FDTs e das análises de similaridade, com uso do programa Blastx, foram identificados 14 genes diferencialmente expressos envolvidos em diferentes processos metabólicos. O padrão de expressão de seis genes sob estresse abiótico foi confirmado por RT-qPCR, e observou-se indução de genes pertencentes a diferentes categorias funcionais, como biossíntese de ácido abscísico, sinalização celular, transportador de prolina e biossíntese de lipídeos de membranas. A expressão desses genes indica sua participação em processos relacionados à proteção dos nódulos ao estresse abiótico.

Termos para indexação: Vigna unguiculata, cDNA-AFLP, fixação biológica de nitrogênio, genômica funcional.

\section{Gene expression induced by abiotic stress in cowpea nodules}

\begin{abstract}
The objective of this work was to evaluate the isolated or concomitant effect of drought and heat stresses on the gene expression of cowpea nodules. The bacterium Bradyrhizobium japonicum (strain BR 3267) was inoculated in cowpea seeds from the cultivar IPA 206 and, 35 days after germination, the plants were subjected to different water availability regimes and to heat stress under greenhouse conditions. To identify differentially expressed genes, the cDNA-AFLP technique was used, and 67 differentially expressed transcript-derived fragments (TDFs) were isolated. After TDFs sequencing and similarity analyses, using the Blastx program, 14 differentially expressed genes were identified, which are involved in different metabolic processes. The expression pattern of six genes under abiotic stress conditions was confirmed by RT-qPCR, and the induction of different functional gene categories, such as abscisic acid biosynthesis, cell signaling, proline transporter, and lipid membrane biosynthesis, was observed. The expression of these genes indicates their participation in processes related to nodule protection under abiotic stresses.
\end{abstract}

Index terms: Vigna unguiculata, cDNA-AFLP, biological nitrogen fixation, functional genomics.

\section{Introdução}

Em condições tropicais, a produtividade agrícola pode ser negativamente afetada por uma série de estresses bióticos e abióticos que alteram o crescimento e o desenvolvimento vegetal. Nesse contexto, destacamse a deficiência de nutrientes, como nitrogênio e fósforo, bem como os estresses decorrentes da baixa disponibilidade hídrica e das altas temperaturas.
A fixação biológica de nitrogênio (FBN) é um processo complexo que pode ser negativamente afetado, em suas diversas etapas, por estresses abióticos, como altas temperaturas e deficit hídrico (Hungria \& Vargas, 2000). Em condições de campo, a interação entre diferentes tipos de estresse tende a maximizar os efeitos deletérios causados por cada estresse individualmente, o que leva a alterações específicas na expressão gênica. Ao longo de sua evolução, as plantas desenvolveram 
uma série de mecanismos de tolerância a estresses abióticos (Iuchi et al., 2000). Contudo, a ativação desses mecanismos varia de acordo com a espécie vegetal, o que determina o seu nível de tolerância ao estresse.

O feijão-caupi (Vigna unguiculata L. Walp) é uma espécie leguminosa cultivada no semiárido nordestino (Freire Filho et al., 2005), em pequenas áreas na Amazônia e, ultimamente, no Cerrado, onde é cultivada em áreas de grandes produtores agrícolas dos estados do Piauí e do Maranhão (Zilli et al., 2006). Além disso, no Nordeste, onde o feijão comum (Phaseolus vulgaris L.) comumente não se desenvolve de forma adequada, em razão de características edafoclimáticas, o cultivo do feijão-caupi é importante, por se tratar de espécie capaz de suportar as elevadas temperaturas e as secas comuns na Região (Freire Filho et al., 2005). O amplo potencial adaptativo (Ehlers \& Hall, 1997), a capacidade de se associar simbioticamente com bactérias diazotróficas (fixadoras de nitrogênio) (Zilli et al., 2006) e a tolerância a estresses ambientais são características importantes para o cultivo do feijão-caupi, para as quais é relevante que se identifique os genes expressos nos nódulos associados a elas (Simões-Araújo et al., 2008). A alteração no padrão de expressão desses genes pode, direta ou indiretamente, conferir boa capacidade de FBN mesmo sob condições limitantes.

O objetivo deste trabalho foi avaliar o efeito isolado ou simultâneo dos estresses hídrico e térmico na expressão gênica, em nódulos de feijão-caupi.

\section{Material e Métodos}

O experimento com choque térmico e restrição hídrica foi conduzido em casa de vegetação, na Embrapa Agrobiologia, Seropédica, RJ. Para isso, sementes de feijão-caupi da cultivar IPA 206 foram superficialmente desinfestadas e semeadas em vasos de plástico $(500 \mathrm{~mL})$ contendo, como substrato, uma mistura de areia/vermiculita, na proporção de $2: 1\left(\mathrm{v} \mathrm{v}^{-1}\right)$, previamente esterilizada. Em seguida, as sementes foram inoculadas com 1,0 mL da estirpe BR 3267 de Bradyrhizobium japonicum previamente crescida em meio YM durante cinco dias, a $30^{\circ} \mathrm{C}$ e sob agitação de $120 \mathrm{rpm}$. Utilizou-se o delineamento experimental inteiramente casualizado, com três repetições e dois regimes de disponibilidade hídrica, além de estresse térmico de $44^{\circ} \mathrm{C}$ por 30 e $60 \mathrm{~min}$.
As plantas foram mantidas em casa de vegetação a $28 \pm 3^{\circ} \mathrm{C}$, com fornecimento de solução nutritiva de Norris, conforme Gruzman \& Döbereiner (1968), isenta de nitrogênio, até o momento da coleta. Inicialmente, cinco sementes foram plantadas e, aos sete dias após a germinação, foi realizado o desbaste, tendo-se mantido apenas três plantas por vaso.

Aos 35 dias após a germinação, as plantas foram submetidas a dois regimes de disponibilidade hídrica: irrigação plena à capacidade de campo e restrição hídrica por suspensão da irrigação. As coletas dos nódulos de feijão-caupi foram realizadas 48, 72 e 96 horas após o início do período de restrição hídrica, e o valor do conteúdo relativo de água (CRA), utilizado como indicador do nível de estresse hídrico, foi determinado em cada coleta.

Parte das plantas submetidas à restrição hídrica por 72 horas foi submetida a estresse térmico de $44^{\circ} \mathrm{C}$, por 30 e 60 min. Para a aplicação do tratamento térmico, as plantas foram transferidas para câmara com temperatura controlada. Uma parcela das plantas foi submetida à 1 hora de estresse térmico, reidratada à capacidade de campo e, em seguida, coletada 1 hora após a reidratação (recuperação).

Para a extração do RNA total dos nódulos de feijão-caupi, foi utilizado o reagente comercial Trizol Reagent Total RNA Isolation System II (Invitrogen, Carlsbad, CA, EUA), de acordo com as especificações do fabricante. O RNA foi quantificado e avaliado em gel de agarose antes do armazenamento a $-70^{\circ} \mathrm{C}$. Para cada tratamento, foram colhidos nove vasos (três vasos para cada tempo de coleta), no total de nove plantas por repetição (vaso) e 27 plantas por tratamento.

O RNA mensageiro (mRNA) foi purificado a partir de 1,0 mg de RNA total obtido dos nódulos. Para a síntese do cDNA dupla-fita, foram utilizados $2,0 \mu \mathrm{g}$ de mRNA purificado com o kit PolyATtract mRNA Isolation Systems II (Promega, Madison, WI, EUA) e com o kit RiboClone - Universal RiboClone cDNA Synthesis System (Promega, Madison, WI, EUA), segundo as especificações do fabricante.

O cDNA obtido dos nódulos de feijão-caupi em diferentes condições de estresse foi utilizado para o cDNA-AFLP, realizado de acordo com Bachem et al. (1996). Os fragmentos de cDNA foram digeridos com as enzimas de restrição EcoRI/MseI e ligados a oligonucleotídeos adaptadores. A reação de ligação foi diluída (1:10) e utilizada nas reações de pré-amplificação 
e amplificação seletiva, conforme Simões-Araújo et al. (2002).

O material da amplificação seletiva foi submetido à eletroforese em gel de poliacrilamida (acrilamida/ bisacrilamida 19:1) corado com nitrato de prata, tendose utilizado o procedimento descrito por Creste et al. (2001).

Após a coloração do gel de poliacrilamida, as bandas correspondentes aos FDTs diferencialmente expressos foram excisadas do gel e eluídas em 100 $\mu \mathrm{L}$ de tampão de PCR $2 \mathrm{X}-40 \mathrm{mmol} \mathrm{L}{ }^{-1}$ Tris- $\mathrm{HCl}$ $(\mathrm{pH} 8,4)$ e $100 \mathrm{mmol} \mathrm{L}^{-1} \mathrm{KCl}-$, a $37^{\circ} \mathrm{C}$ por 16 horas $\mathrm{e}$, adicionalmente, a $95^{\circ} \mathrm{C}$ por 15 min. Cada FDT foi reamplificado por PCR, tendo-se utilizado os iniciadores $\quad E c o$ RI +0 (GACTGCGTACCAATTC) e $M s e \mathrm{I}+0$ (GATGAGTCCTGAGTAA), seguido do sequenciamento em MegaBACE 1000 Analysis Systems (GE Healthcare, Buckinghamshire, Reino Unido).

As sequências obtidas foram submetidas a análises de similaridade com sequências depositadas no banco da base de sequências do National Center for Biotechnology Information (NCBI), com uso do programa Blastx (Altschul et al., 1997). Os FDTs cujas sequências apresentaram similaridade com os genes descritos na literatura, e que foram considerados mais relevantes para o processo de tolerância a estresses abióticos, tiveram o seu perfil de expressão avaliado por RT-qPCR.

As reações de RT-qPCR foram realizadas com três repetições biológicas para cada tratamento. Além disso, para cada repetição biológica, foram realizadas três repetições técnicas a partir da mesma diluição de cDNA (1:50). A $10 \mu \mathrm{L}$ de cDNA fita simples, foram adicionados $4,3 \mu \mathrm{L}$ de $\mathrm{H}_{2} \mathrm{O}$ livre de nucleases, $2,0 \mu \mathrm{L}$ de tampão de PCR 10X - $200 \mathrm{mmol} \mathrm{L}^{-1}$ Tris- $\mathrm{HCl}(\mathrm{pH} \mathrm{8,4)}$ e $500 \mathrm{mmol} \mathrm{L}^{-1} \mathrm{KCl}-, 1,2 \mu \mathrm{L}$ de $\mathrm{MgCl}_{2}\left(50 \mathrm{mmol} \mathrm{L}^{-1}\right)$, $0,2 \mu \mathrm{L}$ de cada iniciador $\left(10 \mathrm{pmol} \mu \mathrm{L}^{-1}\right), 2,0 \mu \mathrm{L}$ de SYBR Green I nucleic acid gel stain (Molecular Probes, Paisley, Reino Unido) diluído em $\mathrm{H}_{2} \mathrm{O}$ (1:10.000) e $0,05 \mu \mathrm{L}$ da enzima Platinum Taq DNA polimerase 5,0 u $\mu \mathrm{L}^{-1}$ (Invitrogen, Carlsbad, CA, EUA).

Os experimentos de RT-qPCR foram realizados no equipamento 7500 Fast Real-Time PCR System (Applied Biosystems, Carlsbad, CA, EUA). Após a ativação da enzima Platinum Taq DNA polimerase por 5 min a $94^{\circ} \mathrm{C}$, a reação prosseguiu por 40 ciclos de desnaturação a $94^{\circ} \mathrm{C}$ por $15 \mathrm{~s}$, anelamento a $60^{\circ} \mathrm{C}$ por $10 \mathrm{~s}$ e extensão a $72^{\circ} \mathrm{C}$ por $15 \mathrm{~s}$. Ao final de cada ciclo, os dados de fluorescência foram coletados a $60^{\circ} \mathrm{C}$ por $35 \mathrm{~s}$. Controles negativos para cada iniciador foram incluídos, tendo-se utilizado $\mathrm{H}_{2} \mathrm{O}$ livre de nucleases em substituição ao cDNA molde.

Para a determinação da expressão relativa, os valores do ciclo limiar $(\mathrm{Ct})$, para cada amostra, foram obtidos a partir de dados brutos de fluorescência, com uso do programa Miner (Zhao \& Russel, 2005). Os valores de Ct foram utilizados para a quantificação relativa (RQ), associada ao controle hidratado $(\mathrm{RQ}=1)$, para cada tempo de coleta, pela equação $\mathrm{RQ}=2^{-\Delta \Delta \mathrm{Ct}}$, conforme Livak \& Schmigtten (2001). Como normalizador, utilizou-se o gene $V u$ UBQ28 (poliubiquitina enzima 28), previamente selecionado como controle endógeno para análise da expressão gênica em nódulos de feijão-caupi sob condições de estresse abiótico.

Os dados de expressão gênica, representativos das três repetições biológicas independentes para cada tratamento, foram submetidos à análise de variância, com uso do programa Sisvar 4.2 (Ferreira, 2008). As médias foram comparadas pelo teste de Scott-Knott, a $5 \%$ de probabilidade. A reprodutibilidade e a precisão dos valores de RQ obtidos foram estimadas pelos valores de erro-padrão da média entre as repetições biológicas.

\section{Resultados e Discussão}

Os valores do CRA das plantas (Figura 1) foram utilizados como indicador fisiológico do nível de estresse hídrico. Como esperado, houve declínio do CRA das plantas ao longo do período de

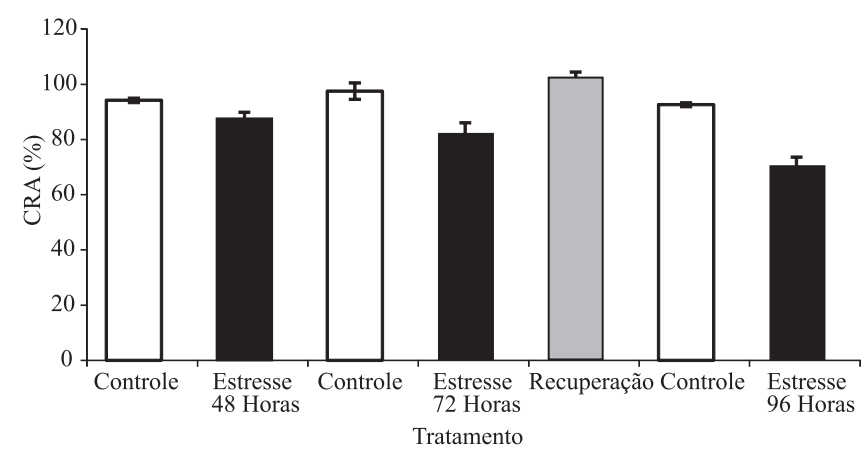

Figura 1. Valores do conteúdo relativo de água (CRA) de plantas de feijão-caupi (Vigna unguiculata) submetidas a diferentes períodos de restrição hídrica (48, 72 e 96 horas). Média de três repetições biológicas independentes. $\mathrm{O}$ estresse térmico de $44^{\circ} \mathrm{C}$ por 30 e 60 min foi aplicado 72 horas após o início do período de restrição hídrica. 
restrição hídrica. Após 48 e 72 horas sem irrigação, o CRA diminuiu para $87,66 \pm 1,28$ e $82,09 \pm 2,29$, respectivamente. Valores de CRA em torno de $80 \%$ indicam nível de estresse moderado. Esse decréscimo foi ainda mais pronunciado em plantas sob restrição hídrica de 96 horas, as quais atingiram CRA médio de $70,27 \pm 1,93 \%$ (estresse severo). Após a reidratação, foi observado valor de CRA de $101,73 \pm 1,86 \%$, o que indica que o tratamento de estresse hídrico associado ao estresse térmico não foi letal.

Foram considerados como diferencialmente expressos os FDTs presentes apenas no tratamento de estresse, ou com variação na intensidade das bandas nas diferentes condições de estresse avaliadas (Figura 2).
O número de FDTs considerados constitutivos e os diferencialmente expressos para cada combinação de oligonucleotídeos foi bastante variável, tendo-se obtido total de 67 FDTs. Foram obtidos o mínimo de três fragmentos, para a combinação II de iniciadores (Mse I+CAA/EcoRI+A), e o máximo de 11 fragmentos, para a combinação III (MseI+AG/EcoRI+ACC). Esta variação tem sido observada na literatura. Zheng et al. (2004), ao utilizar a técnica de cDNA-AFLP para identificação dos genes induzidos por estresse hídrico em milho, verificaram variação no número de FDTs em função da combinação de iniciadores utilizados.

A partir da combinação de oligonucleotídeos III (MseI+AG/EcoRI+ACC) (Figura 2), que apresentou o
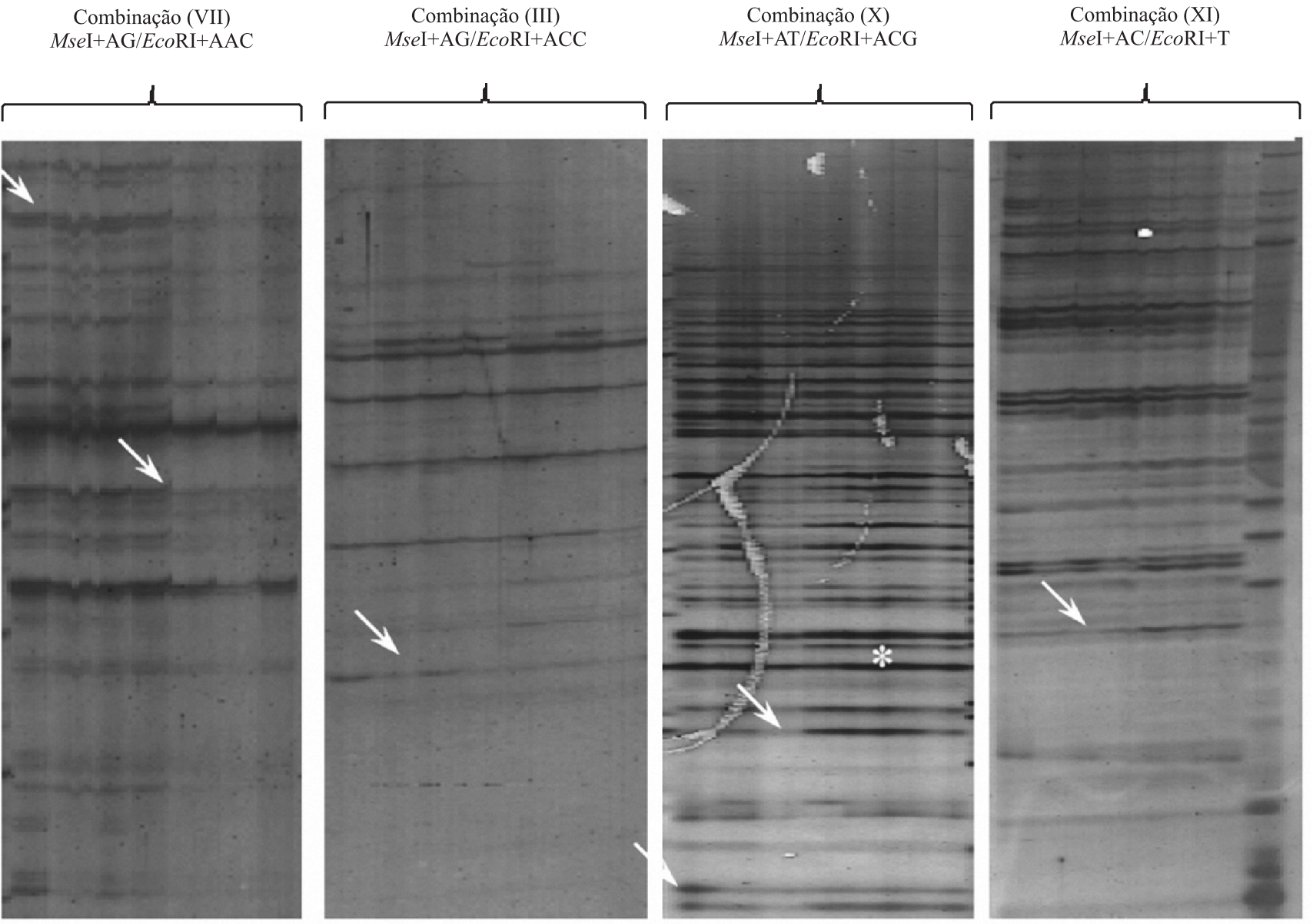

Figura 2. Regiões dos géis de poliacrilamida de fragmentos derivados de transcritos (FDTs) diferencialmente expressos obtidos a partir das combinações de iniciadores, MseI+AG/EcoRI+AAC (VII), MseI+AG/EcoRI+ACC (III), MseI+AT/ $E c o R I+A C G(X)$ e $M s e I+A C / E c o R I+T(X I)$, utilizadas na análise de cDNA-AFLP. As amostras estão dispostas de 1-7 para cada combinação de iniciadores: 1, controle de 48 horas; 2, 48 horas de restrição hídrica; 3, controle de 72 horas; 4 , 72 horas de restrição hídrica; 5,72 horas de restrição hídrica mais 30 min a $44^{\circ} \mathrm{C} ; 6,72$ horas de restrição hídrica mais 60 min a $44^{\circ} \mathrm{C}$; e 7 , recuperação das plantas submetidas ao estresse térmico de $60 \mathrm{~min}$ a $44^{\circ} \mathrm{C}$. Setas em branco indicam FDTs diferencialmente expressos; * - FDT constitutivo. 
maior número de fragmentos polimórficos, foi possível obter 166 FDTs, dos quais 11 foram diferencialmente expressos e reamplificáveis. Decorosi et al. (2005), ao avaliar o perfil de transcritos na bactéria Cupriavidus metallidurans em resposta ao cromato $\left(\mathrm{K}_{2} \mathrm{CrO}_{4}\right)$, utilizaram duas combinações de iniciadores e isolaram 131 FDTs, dos quais nove foram diferencialmente expressos, o que correspondeu a aproximadamente $7 \%$ dos FDTs. Simões-Araújo et al. (2002), ao utilizar seis combinações de oligonucleotídeos, obtiveram 600 FDTs em nódulos de feijão-caupi, dos quais 64 foram diferencialmente expressos em reposta ao estresse térmico. Esses resultados são indicativos de que a eficiência na obtenção de FDTs diferencialmente expressos é extremamente dependente de variáveis, como complexidade do organismo estudado, combinação de iniciadores utilizada nas reações de amplificação e número de tratamentos aplicados. Para organismos que apresentam genoma sequenciado, uma alternativa para aumentar o número de FDTs diferencialmente expressos é a realização de experimento inicial com cDNA-AFLP in silico, para se selecionar as melhores combinações de iniciadores a serem utilizadas para o experimento in vivo.

No presente trabalho, 54 dos fragmentos diferencialmente expressos identificados foram reamplificados e purificados a partir do gel de agarose, dos quais 36 foram sequenciados. As análises de similaridade das sequências permitiram identificar alguns genes envolvidos em diferentes processos metabólicos, como metabolismo antioxidante da célula, metabolismo de lipídeos, transporte de prolina, síntese de açúcares, vias de transdução de sinal, inibidores de proteases e biossíntese de ácido abscísico (ABA) (Tabela 1). Embora essas análises tenham sido dificultadas, provavelmente em razão do tamanho dos fragmentos obtidos e do baixo número de sequências de feijão-caupi presentes nos bancos de dados, observou-se alto valor E para grande parte dos FDTs. Quatorze FDTs apresentaram similaridade com genes potencialmente envolvidos nas respostas vegetais a estresses abióticos. As sequências similares a seis FDTs foram obtidas do banco de dados e utilizadas para desenhar iniciadores que foram avaliados por RT-qPCR, para confirmação do padrão de expressão desses genes.

$\mathrm{O}$ perfil de expressão dos genes $V u$ CPRD8 ( $V u$ NSR47), $V u$ CPRD12 e $V u$ CPRD14 (VuNSR44), $V u$ CPRD65 ( $V u$ NSR49), $V u$ DGD1 (VuNSR4) e $V u$ CDPK ( $V u$ NSR10) (Tabela 1) foi avaliado por RT-qPCR, com eficiência de amplificação próxima de $100 \%$, o que permitiu a utilização do método $2^{-\Delta \Delta \mathrm{CT}}$ para quantificação relativa da expressão gênica (Livak \& Schmigtten, 2001). A alteração no perfil de expressão desses genes (Figuras 3 e 4) indica a sua participação nos mecanismos de proteção ao estresse hídrico e térmico nos nódulos durante a FBN. Os genes identificados pertencem a diferentes categorias funcionais, que incluem: produção e conversão de energia ( $V u C P R D 8)$,

Tabela 1. Análise de similaridade das sequências dos fragmentos derivados de transcritos (FDTs) diferencialmente expressos com as sequências depositadas no banco de dados do National Center for Biotechnology Information (NCBI), com uso do programa Blastx.

\begin{tabular}{|c|c|c|c|c|c|}
\hline$\overline{\mathrm{FDT}^{(1)}}$ & Sequência obtida $(\mathrm{pb})$ & Provável função & Valor E & ID $(\%)^{(2)}$ & $\operatorname{Cob}(\%)^{(3)}$ \\
\hline$V u$ NSR10 & 81 & Proteína quinase cálcio-dependente [Vigna radiata] (AAC49405.1) & 0,014 & 38 & 88 \\
\hline$V u$ NSR30 & 212 & Proteína-2 de resistência específica [Vigna radiata] (BAC22500.1) & 0,021 & 71 & 9 \\
\hline$V u$ NSR 12 & 162 & Leghemoglobina redutase férrica [Vigna unguiculata] (AAD53185.1|AF181096_1) & 0,079 & 67 & 16 \\
\hline$V u$ NSR24 & 159 & Isoforma III da amido sintase [Vigna unguiculata] (CAB40374.1|) & 0,021 & 38 & 30 \\
\hline \multirow{2}{*}{$V u$ NSR44 } & 258 & Proteína CPRD12 [Vigna unguiculata] (BAA13541.1) & $1 \mathrm{e}-08$ & 58 & 65 \\
\hline & 149 & Proteína CPRD14 [Vigna unguiculata] (BAA12161.1) & 0,010 & 53 & 30 \\
\hline$V u$ NSR13 & 129 & Isoforma $\mathrm{V}$ da amido sintase [Vigna unguiculata] (CAB40375.1) & 0,005 & 47 & 39 \\
\hline$V u$ NSR4 & 92 & Digalactosildiacilglicerol sintase 1 [Vigna unguiculata] (ABA55727.1) & 0,022 & 58 & 39 \\
\hline$V u$ NSR47 & 167 & Proteína CPRD8 (enzima “old yellow") [Vigna unguiculata] (BAA12160.1) & 0,055 & 50 & 25 \\
\hline$V u$ NSR49 & 144 & Proteína CPRD65 [Vigna unguiculata] (BAB11932.1) & 0,022 & 33 & 31 \\
\hline$V u$ NSR 19 & 176 & Transportador de prolina 2 [Vigna unguiculata] (BAG06274.2) & $7 e-04$ & 38 & 57 \\
\hline$V u$ NSR28 & 101 & Fosfatidilglicerol fosfato sintase [Vigna unguiculata] (ABA55724.1) & 0,002 & 58 & 35 \\
\hline$V u$ NSR50 & 71 & Inibidor de protease IIc $(1102213 \mathrm{C})$ & 0,016 & 60 & 42 \\
\hline$V u$ NSR22 & 96 & Fosfolipase C fosfoinositídeo específica [Vigna unguiculata] (AAB41107.1) & 0,006 & 62 & 40 \\
\hline
\end{tabular}

(1) VuNSR, Vigna unguiculata "nodule stress responsive". (2)Identidade máxima no BLASTx. (3)Cobertura da sequência (\%) após alinhamento no BLASTx. Valores entre parênteses referem-se ao número de acesso no NCBI. Bancos utilizados na busca: Vigna (Taxid: 3913), Vigna unguiculata (Taxid: 3917) e Vigna unguiculata Walp. subsp. alba (Taxid: 460247). As análises foram realizadas em 25/2/2012. 
metabolismo antioxidante da célula (VuCPRD12 e $V u$ CPRD14), metabolismo de lipídeos da membrana ( $V u$ DGD1), cascatas de transdução de sinal ( $V u C D P K)$ e síntese de ABA (VuCPRD65). Na literatura, há relatos da indução de $V u$ CPRD8, $V u$ CPRD12, $V u$ CPRD14 e $V u$ CPRD65 em folhas de feijão-caupi, em reposta à desidratação progressiva (Iuchi et al., 1996b, 2000). No presente trabalho, a indução desses genes foi observada, pela primeira vez, em nódulos, o que indica que parte dos mecanismos moleculares ativados em folhas durante o estresse pode, também, atuar nos nódulos e contribuir para a manutenção da FBN sob condições adversas. Contudo, estudos funcionais mais detalhados precisam ser realizados para confirmar esta hipótese.

O FDT $V u$ NSR44 apresentou similaridade ao $V u$ CPRD14, enquanto os resultados de RT-qPCR mostraram que o $V u C P R D 14$ foi induzido por estresse hídrico ao longo dos três períodos de restrição hídrica (Figura 3 A). No entanto, seu perfil de expressão parece não ter sido influenciado pelo tratamento térmico (Figura $4 \mathrm{~A}$ ). O gene $V u \mathrm{CPRD} 14$, induzido em folhas de feijão-caupi submetido à desidratação progressiva (Iuchi et al., 1996a), apresenta homologia a dihidroflavonol-4-reductase (DFR) e vestitone reductase (VR), ambas envolvidas na via de biossíntese de flavonoides (Treutter, 2006). Os flavonoides apresentam propriedades antioxidantes, e a sua função em plantas, entre outras, está relacionada à resposta a estresses. Balakumar et al. (1993) relataram acúmulo desses compostos em resposta à seca. Em arroz, os genes $O s$ Dfr e OsAns, envolvidos na biossíntese de flavonoides, foram induzidos por seca, salinidade e ABA (Ithal \& Reddy, 2004). A indução de $V u$ CPRD14 nos nódulos em condições de estresse hídrico pode estar associada ao aumento na biossíntese de flavonoides, necessário para reduzir os danos oxidativos ocasionados pelo estresse.

O FDT $V u$ NSR49 apresentou similaridade ao gene $V u$ CPRD65, identificado em folhas de cultivar de feijão-caupi tolerante à seca (IT84S-2246-4) (Iuchi et al., 1996b). Em razão da sua homologia com a 9-cis-epoxicarotenoide dioxigenease (NCED), esse gene foi posteriormente renomeado para $V u$ NCED1 (Iuchi et al., 2000). Essa enzima está envolvida na síntese de $\mathrm{ABA}$ e catalisa a reação de clivagem de epoxicarotenoides para produzir xantoxina, o primeiro intermediário de 15 carbonos na via de biossíntese de ABA em plantas (Nambara \& Marion-Poli, 2005).
Estudos bioquímicos indicam que a clivagem de 9-cis-epoxicarotenoide dioxigenease é uma etapa chave na via biossíntese de ABA (Kende \& Zeevaart, 1997), o que torna essa enzima extremamente importante na via de biossíntese deste hormônio.

$\mathrm{Na}$ literatura, têm-se observado que a síntese de ABA, além de controlar processos fundamentais de desenvolvimento em plantas, está relacionada a estresses abióticos, como baixas temperaturas, condições de seca e alta salinidade (Wan \& Li, 2006; Clement et al., 2008). Em Arabidopsis, há pelo menos sete genes relacionados ao NCED, dos quais o AtNCED3 está especificamente envolvido nas respostas ao deficit hídrico. Plantas transgênicas $A t \mathrm{NCED} 3$ "sense" (superexpressando o AtNCED3) apresentaram maior tolerância à seca, enquanto plantas nas quais o $A t \mathrm{NCED} 3$ foi reprimido por RNA "antisense" (AtNCED3 "antisense") ou inserção de T-DNA (T-DNA-AtNCED3) foram mais sensíveis (Iuchi et al., 2001). Resultados semelhantes foram obtidos por Wan \& Li (2006), em que a expressão ectópica de $A h \mathrm{NCED} 1$, um gene que codifica para 9-cis-epoxicarotenoide dioxigenase em amendoim (Arachis hypogaea L.), foi correlacionada ao acúmulo de ABA nos tecidos em resposta ao deficit hídrico, o que aumentou a tolerância das plantas ao estresse.

Os dados de RT-qPCR mostraram que o $V u$ CPRD65 ( $V u$ NCED1) foi induzido em todas as condições de estresse avaliadas e que a sua expressão em nódulos de feijão-caupi foi observada após a aplicação do estresse térmico (Figura $4 \mathrm{~B}$ ); contudo, observouse forte indução em reposta ao deficit hídrico apenas após 96 horas (Figura 3 B). A indução de $V u$ NCED1 em nódulos de feijão-caupi pode estar relacionada à biossíntese de ABA. Clement et al. (2008) verificaram que, em nódulos de soja, após cinco dias de deficit hídrico, houve acúmulo de ABA em níveis compatíveis àqueles obtidos em folhas. Portanto, apesar da expressão de $V u$ NCED1 não ter sido observada em raízes de feijão-caupi em resposta ao deficit hídrico (Iuchi et al., 2000), esse gene apresentou perfil de expressão diferente em nódulos. Além disso, uma vez que o ABA atua em vias de transdução de sinal em resposta a estresses, o aumento da sua síntese nos nódulos pode estar associado à indução de genes relacionados à tolerância ao deficit hídrico, o que contribui para a manutenção da FBN nessas condições.

O FDT $V u$ NSR 47 apresentou similaridade ao gene $V u$ CPRD8, descrito pela primeira vez como expresso em resposta ao deficit hídrico (Iuchi et al., 1996b). 
O $V u$ CPRD8 codifica para uma flavoproteína com atividade de oxiredutase relacionada ao grupo de proteínas denominado "old yellow enzyme group". Esta família corresponde a proteínas envolvidas na
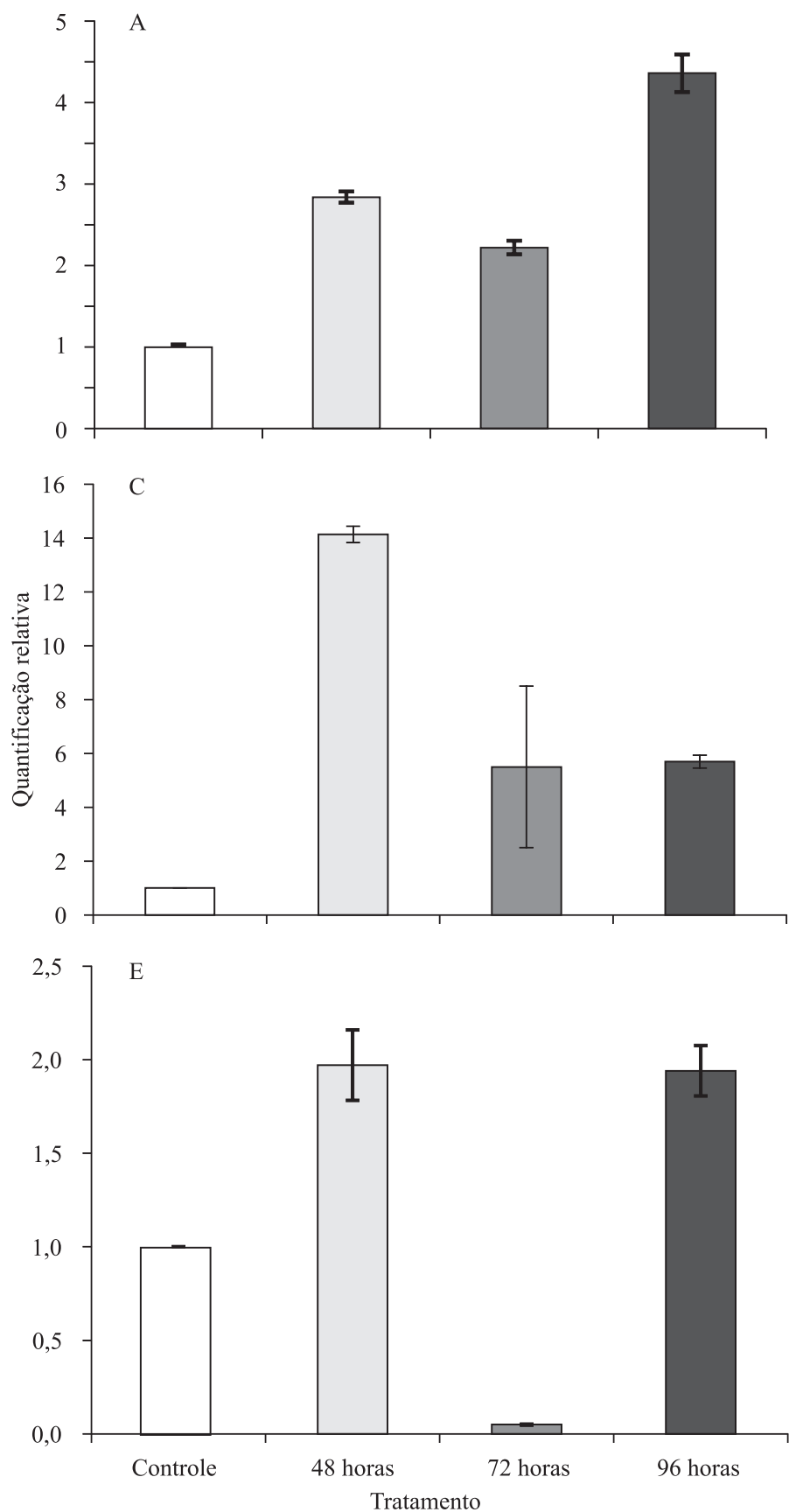

conversão e na produção de energia na célula. Embora a estrutura geral dessas proteínas já tenha sido descrita (Fox \& Karplus, 1994), até o momento, sua função fisiológica permanece desconhecida. A indução de
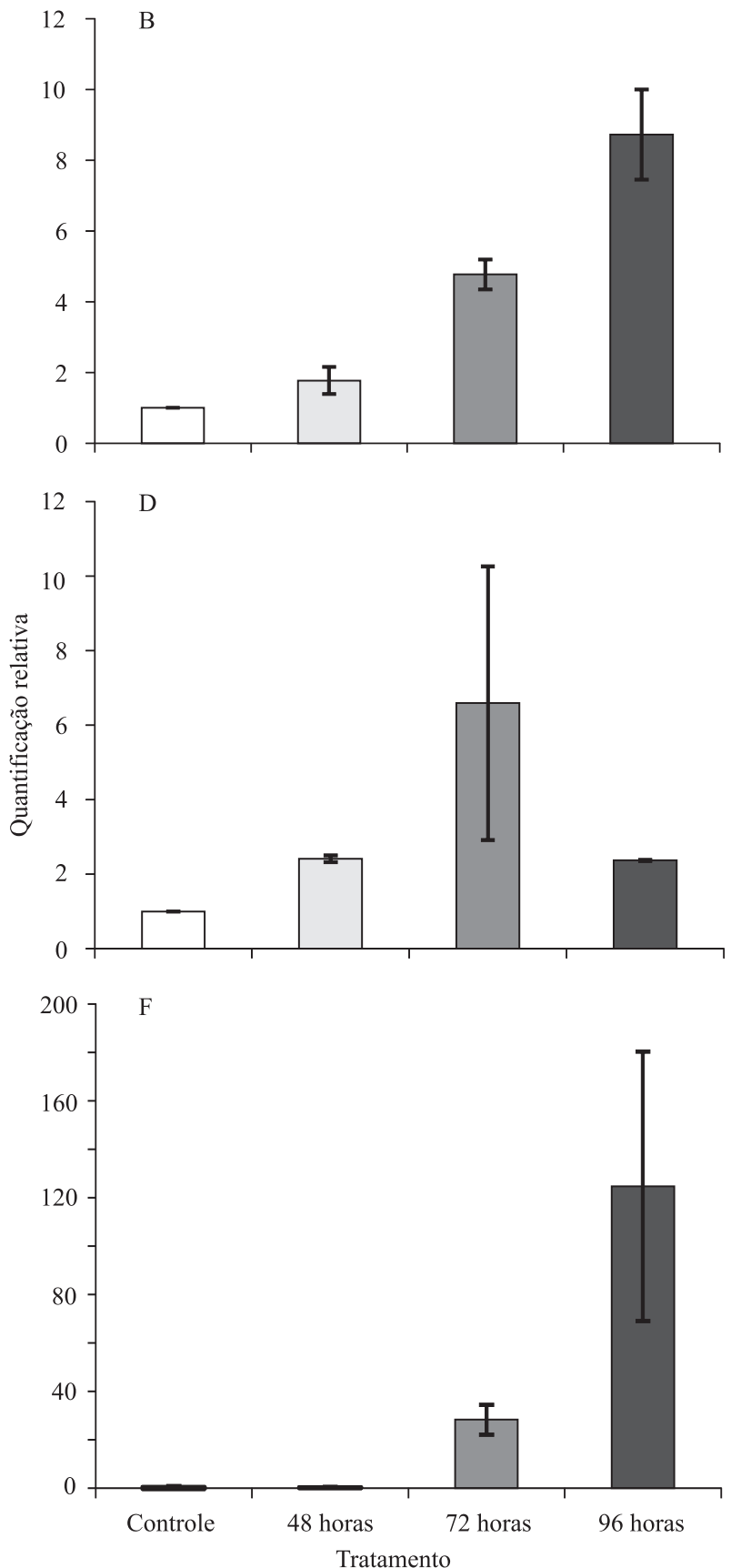

Figura 3. Perfil de expressão dos genes diferencialmente expressos em nódulos de feijão-caupi (Vigna unguiculata) submetido a diferentes regimes de disponibilidade hídrica com uso de RT-qPCR. Controle, plantas plenamente irrigadas submetidas a diferentes períodos de restrição hídrica (48, 72 e 96 horas). Os dados de expressão gênica são representativos de três repetições biológicas independentes para cada tratamento após análise com o programa "Real-Time Miner Tool", para determinação dos valores do ciclo limiar $(\mathrm{Ct})$. A quantificação relativa (RQ) foi calculada por meio da equação: $R Q=2^{-\Delta \Delta C t}$ (Livak \& Schmigtten, 2001). 
$V u$ CPRD8 foi observada em resposta ao estresse hídrico (Figura $3 \mathrm{C}$ ); no entanto, quando em associação ao estresse térmico, os níveis de expressão não diferiram dos do controle (Figura 4 C).
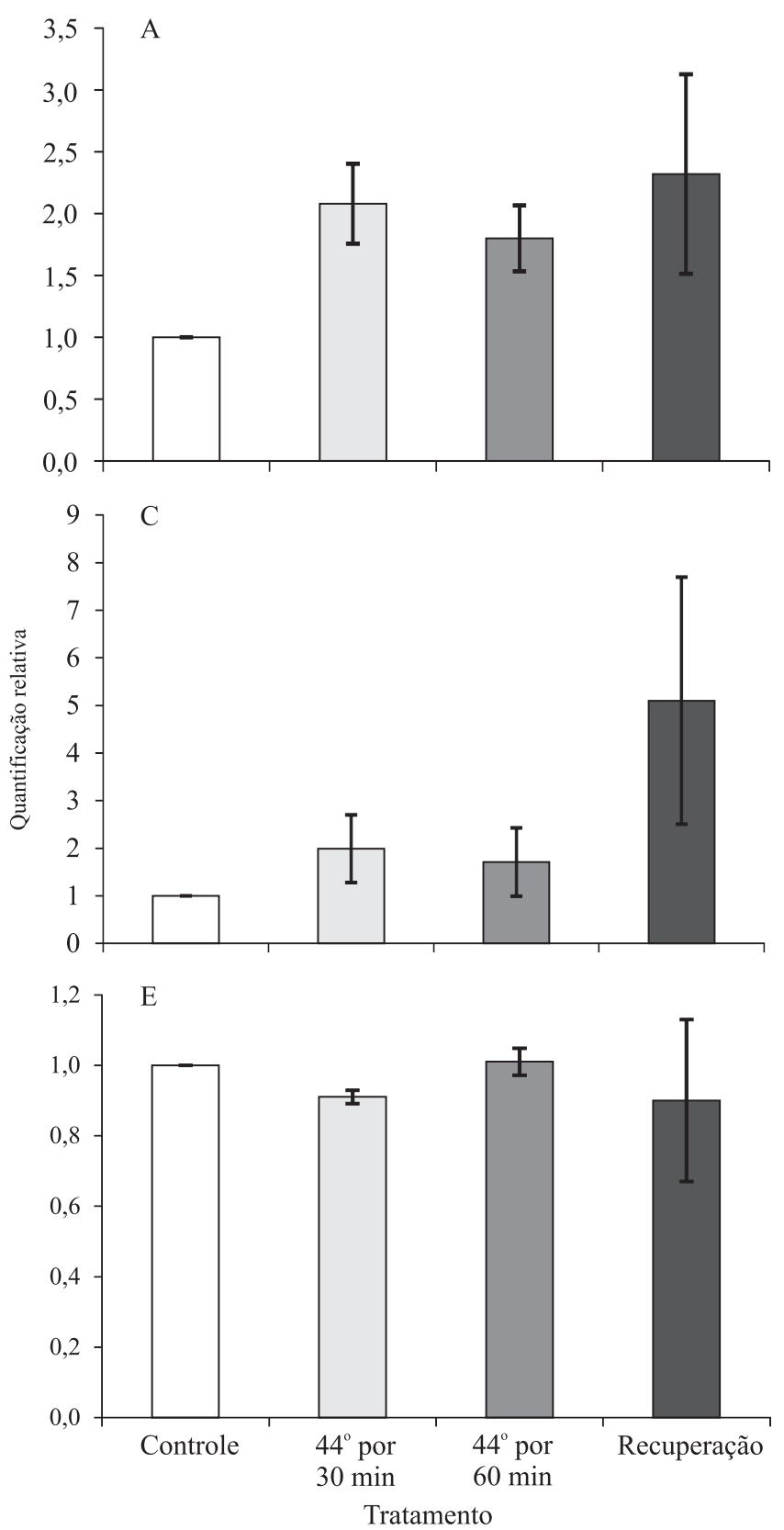

O FDT $V u$ NSR4 apresentou similaridade ao gene que codifica para a enzima digalactosil-diacilglicerol sintase ( $V u$ DGGS1), envolvida na biossíntese de digalactosil-diacilglicerol (DGDG), que, em conjunto
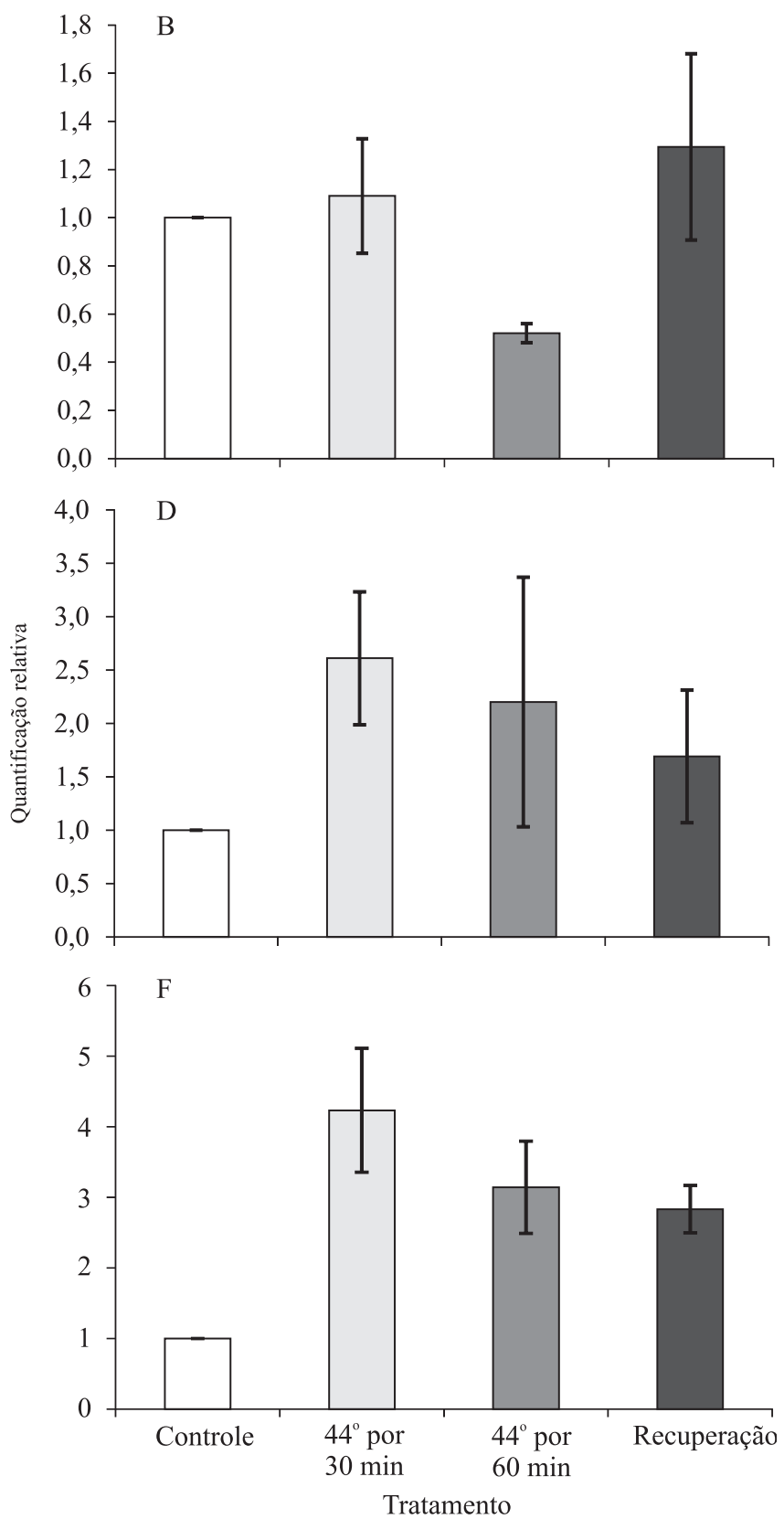

Figura 4. Perfil de expressão dos genes diferencialmente expressos em nódulos de feijão-caupi (Vigna unguiculata) com uso de RT-qPCR. Controle, plantas submetidas a restrição hídrica de 72 horas e subsequente estresse térmico de $44^{\circ} \mathrm{C}$ por $30 \mathrm{e}$ 60 min; e Recuperação, plantas submetidas a restrição hídrica de 72 horas e subsequente estresse térmico, coletadas 1 hora após a reidratação. Os dados de expressão gênica são representativos de três repetições biológicas independentes para cada tratamento após análise com uso do programa "Real-Time Miner Tool", para determinação dos valores do ciclo limiar (Ct).

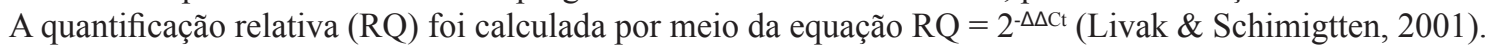


com o monogalactosil-diacilglicerol (MGDG), são os principais componentes do envelope do cloroplasto e da membrana do tilacoide (Torres-Franklin et al., 2007). Interessantemente, foi observada indução de $V u$ DGD1 logo após 48 horas sob estresse hídrico; porém, após 72 horas de estresse, apesar do aumento da expressão de pelo menos seis vezes, em comparação ao controle, não houve diferença significativa (Figura 3 D). Também não foram observadas diferenças significativas entre os níveis de expressão após a aplicação do tratamento térmico (Figura $4 \mathrm{D}$ ), provavelmente em razão do alto desvio-padrão verificado para os valores de RQ neste tempo de coleta. Além disso, após 96 horas sob restrição hídrica, a expressão de $V u$ DGD1 foi induzida, semelhantemente ao observado após 48 horas.

As membranas celulares estão entre as principais estruturas afetadas pelo estresse hídrico. Nessas condições, o metabolismo de lipídeos da membrana é alterado e apresenta função importante na aclimatação ao estresse (Gigon et al., 2004). Torres-Franklin et al. (2007) também observaram acúmulo de DGDG em feijão-caupi em resposta ao deficit hídrico. Em plantas de Arabidopsis thaliana submetidas ao deficit hídrico, foram relatadas alterações no metabolismo de lipídeos de membrana em folhas (Gigon et al., 2004). Embora esse galactosilglicerolipídeo esteja associado, principalmente, ao cloroplasto, verificouse seu acúmulo em membranas não cloroplásticas em resposta ao estresse, o que indica sua participação nos mecanismos de tolerância da planta ao deficit hídrico (Torres-Franklin et al., 2007).

A atividade de FBN depende fundamentalmente de membrana biológica denominada simbiossomo, que estabelece uma interface planta-bactéria, o que possibilita a troca de metabólitos, um dos processos importantes para manutenção da FBN. Em Medicago truncatula, pelo menos 51 proteínas funcionais foram identificadas no simbiossomo, as quais incluíram $\mathrm{H}^{(+)}$-ATPase, ENOD16, ENOD8, nodulina-25, BiP, HSP70 e uma aquaporina multifuncional, entre outras proteínas desconhecidas (Catalano et al., 2004). Assim, a manutenção da integridade do simbiossomo é fundamental para manter a FBN durante o estresse, e alterações no metabolismo dos lipídeos constituintes dessa membrana provavelmente estão relacionadas à proteção contra estresses abióticos, uma vez que alterações estruturais na membrana do simbiossomo podem afetar a atividade de enzimas importantes e, consequentemente, comprometer o processo de FBN.

O FDT $V u$ NSR10 mostrou similaridade com um gene que codifica para uma proteína quinase cálcio-dependente $(V u C D P K)$ envolvida em vias de transdução de sinal (Klimecka \& Muszyńska, 2007). Em nódulos de feijão-caupi, possivelmente há um padrão complexo de expressão de $V u C P D K$, com indução em resposta ao estresse hídrico de 48 e 96 horas e expressão significativamente diminuída em resposta ao estresse hídrico de 72 horas (Figura 3 E). Além disso, não foi observada diferença significativa em relação ao controle absoluto, após a aplicação do estresse térmico associado à restrição hídrica de 72 horas. É provável que a diminuição dos níveis de expressão após 72 horas de estresse hídrico teve algum efeito nos níveis de expressão durante o estresse térmico (Figura $4 \mathrm{E}$ ). A atuação de proteínas quinases cálcio-dependentes nas respostas vegetais ao estresse térmico também foi observada por Kanchiswamy et al. (2010). Possivelmente, essa proteína quinase antecede a expressão de outras proteínas importantes para a resposta ao estresse térmico, como a $V u$ HSP17.7 (Simões-Araújo et al., 2008), por meio da ativação por fosforilação de fatores de transcrição ("heat shock factors" - HSFs), necessários para a expressão das proteínas de choque térmico (Kanchiswamy et al., 2010).

O FDT $V u$ NSR44 apresentou similaridade ao gene $V u$ CPRD12, que codifica uma enzima da família das álcool desidrogenases não metálicas de cadeia curta. Essas proteínas apresentam domínio multifuncional de oxiredutase e atuam em uma variedade de vias metabólicas, que incluem: ácidos graxos, glicose e esteroides (Persson et al., 1991). Iuchi et al. (1996b) isolaram esse gene de uma biblioteca de feijão-caupi em condições de desidratação progressiva. No presente trabalho, a indução de $V u$ CPRD12 foi observada em nódulos em resposta ao estresse hídrico, com maior acúmulo de transcritos após estresse de 96 horas (Figura $3 \mathrm{~F}$ ) e subsequente estresse térmico (Figura $4 \mathrm{~F}$ ). Iuchi et al. (1996b) verificaram que $V u$ CPRD12 não foi induzido por altas temperaturas. Portanto, sua expressão pode estar relacionada ao estresse hídrico de 72 horas associado à aplicação do tratamento térmico. É possível que o VuCPRD12 esteja envolvido na tolerância à seca em plantas. Além disso, foi mostrado, em feijão-caupi, que esse gene também é induzido 
por ABA (Iuchi et al., 1996a). Cabe ressaltar que nódulos apresentam um padrão metabólico complexo, mesmo em condições normais. Sob estresse abiótico, a indução de genes relacionados ao metabolismo de diferentes biomoléculas, como glicose e ácidos graxos, pode auxiliar na manutenção de processos biológicos fundamentais que ocorrem nessa estrutura radicular.

A expressão diferencial dos genes identificados em nódulos de feijão-caupi provavelmente está associada a diferentes mecanismos de proteção da célula contra estresses abióticos, o que contribui de forma direta ou indireta para a manutenção da atividade de FBN nessas condições. A indução de genes pertencentes a diferentes categorias funcionais indica a existência de resposta complexa nos nódulos, que vai desde a percepção do estresse e cascatas de transdução sinal, até a expressão de genes específicos, que atuarão diretamente nas defesas celulares.

A caracterização funcional mais detalhada desses genes pode fornecer uma melhor compreensão dos processos adaptativos desenvolvidos no interior dessas estruturas simbióticas, o que permitiria o desenvolvimento de estratégias biotecnológicas pontuais para maior contribuição da FBN em leguminosas sob condições tropicais.

\section{Conclusões}

1. Os estresses hídrico e térmico provocam complexa alteração na expressão gênica dos nódulos de feijão-caupi.

2. Genes pertencentes a diferentes categorias funcionais são induzidos em resposta aos estresses térmico e hídrico, o que indica a sua participação nos mecanismos de proteção dos nódulos para manutenção da fixação biológica de nitrogênio nessas condições.

3. O padrão de expressão durante todo o período de estresse avaliado (96 horas) difere significativamente entre os diferentes genes, com aumento contínuo dos níveis de expressão em alguns casos.

\section{Agradecimentos}

À Coordenação de Aperfeiçoamento de Pessoal de Nível Superior, pela bolsa concedida; ao Conselho Nacional de Desenvolvimento Científico e Tecnológico, pelo financiamento do equipamento de PCR em tempo real (Processo 479.968/2009-8); à Dra. Janaína Ribeiro Costa Rows, pelo auxílio na análise estatística dos dados; à Empresa Brasileira de Pesquisa Agropecuária, pela disponibilização de infraestrutura para realização do experimento e pelo apoio financeiro.

\section{Referências}

ALTSCHUL, S.F.; MADDEN, T.L.; SCHAFFER, A.A.; ZHANG, J.; ZHANG, Z.; MILLER, W.; LIPMAN, D.J. Gapped BLAST and PSI-BLAST: a new generation of protein database search programs. Nucleic Acids Research, v.25, p.3389-3402, 1997.

BACHEM, C.W.B.; VAN DER HOEVEN, R.S.; DE BRUIJN, S.M.; VREUGDENHIL, D.; ZABEAU, M.; VISSER, R.G. Visualization of differential gene expression using a novel method of RNA fingerprinting based on AFLP: analysis of gene expression during potato tuber development. Plant Journal, v.9, p.745-753, 1996.

BALAKUMAR, T.; VINCENT, V.H.B.; PALIWAL, K. On the interaction of UV-B radiation $(280-315 \mathrm{~nm})$ with water stress in crop plants. Physiologia Plantarum, v.87, p.217-222, 1993

CATALANO, C. M.; LANE, W. S.; SHERRIER, D. J. Biochemical characterization of symbiosome membrane proteins from Medicago truncatula root nodules. Electrophoresis, v.25, p.519-531, 2004.

CLEMENT,M.;LAMBERT,A.;HEROUART,D.;BONCOMPAGNI, E. Identification of new up-regulated genes under drought stress in soybean nodules. Gene, v.426, p.15-22, 2008.

CRESTE, S.; TULMANN NETO, A.; FIGUEIRA, A. Detection of single sequence repeat polymorphisms in denaturing polyacrylamide sequencing gels by silver staining. Plant Molecular Biology Report, v.19, p.299-306, 2001

DECOROSI, F.; VITI, T.; MENGONI, A.; BAZZICALUPO, M.; GIOVANNETTI, L. Improvement of the cDNA-AFLP method using fluorescent primers for transcription analysis in bacteria. Journal of Microbiological Methods, v.63, p.211-215, 2005.

EHLERS, J.D.; HALL, A.E. Cowpea (Vigna unguiculata L. Walp). Field Crops Research, v.53, p.187-204, 1997.

FERREIRA, D.F. Sisvar: um programa para análises e ensino de estatística. Revista Symposium, v.6, p.36-41, 2008.

FOX, K.M.; KARPLUS, P.A. Old yellow enzyme at 2 A resolution: overall structure, ligand binding, and comparison with related flavoproteins. Structure, v.2, p.1089-1105, 1994.

FREIRE FILHO, F.R.; LIMA, J.A. de A.; RIBEIRO, V.Q. Feijão-caupi: avanços tecnológicos. Brasília: Embrapa Informação Tecnológica, 2005. 519p.

GIGON, A.; MATOS, A.-R.; LAFFRAY, D.; ZUILY-FODIL, Y.; PHAM-THI, A. Effect of drought stress on lipid metabolism in the leaves of Arabidopsis thaliana (Ecotype Columbia). Annals of Botany, v.94, p.345-351, 2004.

GRUZMAN, I.; DÖBEREINER, J. Efect of Azotobacter chroococcum and tryptophan on the inoculation of soybean (Glycine $\max$ (L.) Merr.) with Rhizobium japonicum. In: REUNIÃO LATINO AMERICANA SOBRE INOCULANTES PARA LEGUMINOSAS, 4., 1968. Anais. Porto Alegre: Secretaria de Agricultura, 1968. p.46-57. 
HUNGRIA, M.; VARGAS, M.A.T. Environmental factors affecting $\mathrm{N}_{2}$ fixation in grain legumes in the tropics, with an emphasis on Brazil. Field Crops Research, v.65, p.151-164, 2000.

ITHAL, N.; REDDY, A.R. Rice flavonoid pathway genes, OsDfr and OsAns, are induced by dehydration, high salt and ABA, and contain stress responsive promoter elements that interact with the transcription activator, OsC1-MYB. Plant Science, v.166, p.1505-1513, 2004.

IUCHI, S.; KOBAYASHI, M.; TAJI, M.; NARAMOTO, M.; SEKI, M.; KATO, T.; TABATA, S.; KAKUBARI, Y.; YAMAGUCHI-SHINOZAKI, K.; SHINOZAKI, K. Regulation of drought tolerance by gene manipulation of 9-cis-epoxycarotenoid dioxygenase, a key enzyme in abscisic acid biosynthesis in Arabidopsis. The Plant Journal, v.27, p.325-333, 2001.

IUCHI, S.; KOBAYASHI, M.; YAMAGUCHI-SHINOZAKI, K.; SHINOZAKI, K. A stress-inducible gene for 9-cis-epoxycarotenoid dioxygenase involved in abscisic acid biosynthesis under water stress in drought tolerant cowpea. Plant Physiology, v.123, p.553-562, 2000.

IUCHI, S.; YAMAGUCHI-SHINOZAKI, K.; URAO, T.; SHINOZAKI, K. Characterization of two cDNAs for novel drought-inducible genes in the highly drought-tolerant cowpea. Journal of Plant Research, v.109, p.415-424, 1996a.

IUCHI, S.; YAMAGUCHI-SHINOZAKI, K.; URAO, T.; TERAO, T.; SHINOZAKI, K. Novel drought-inducible genes in the highly drought tolerant cowpea: cloning of cDNAs and analysis of the expression of the corresponding genes. Plant and Cell Physiology, v.8, 1073-1082, 1996b.

KANCHISWAMY, C.N.; MUROI, A.; MAFFEI, M.E.; YOSHIOKA, H.; SAWASAKI, T.; ARIMURA, G. $\mathrm{Ca}^{2+}$-dependent protein kinases and their substrate $\mathrm{HsfB} 2 \mathrm{a}$ are differently involved in the heat response signaling pathway in Arabidopsis. Plant Biotechnology, v.27, p.469-473, 2010.

KENDE, H.; ZEEVAART, J.A.D. The five classical plant hormones. Plant Cell, v.9, p.1197-1210, 1997.

KLIMECKA, M.; MUSZYŃSKA, G. Structure and functions of plant calcium-dependent protein kinases. Acta Biochimica Polonica, v.54, p.219-233, 2007.

LIVAK, K.J.; SCHMITTGEN, T.D. Analysis of relative gene expression data using real-time quantitative PCR and the 2(-Delta Delta C(T)) method. Methods, v.25, p.402-408, 2001.
NAMBARA, E.; MARION-POLL, A. Abscisic acid biosynthesis and catabolism. Annual Review of Plant Biology, v.56, p. 165-185, 2005.

PERSSON, B.; KROOK, M.; JORNVALL, H. Characteristics of short-chain alcohol dehydrogenases and related enzymes. European Journal of Biochemistry, v.200, p.537-543, 1991.

SIMÕES-ARAÚJO, J.L.; ALVES-FERREIRA, M.; RUMJANEK, N.G.; MARGIS-PINHEIRO, M. $V u$ NIP1 (NOD26-like) and $V u$ HSP17.7 gene expression are regulated in response to heat stress in cowpea nodule. Environmental and Experimental Botany, v.63, p.256-265, 2008.

SIMÕES-ARAÚJO, J.L.; RODRIGUES, R.L.; GERHARDT, L.B. deA.;MONDEGO,J.M.C.;ALVES-FERREIRA, M.; RUMJANEK, N.G.; MARGIS-PINHEIRO, M. Identification of differentially expressed genes by cDNA-AFLP technique during heat stress in cowpea nodules. FEBS Letters, v.515, p.44-50, 2002.

TORRES-FRANKLIN, M.-L.; GIGON, A.; DE MELO, D.F.; ZUILY-FODIL, Y.; PHAM-THI, A. Drought stress and rehydration affect the balance between MGDG and DGDG synthesis in cowpea leaves. Physiologia Plantarum, v.131, p.201-210, 2007.

TREUTTER, D. Significance of flavonoids in plant resistance: a review. Environmental Chemistry Letters, v.4, p.147-157, 2006.

WAN, X.R.; LI, L. Regulation of ABA level and water-stress tolerance of Arabidopsis by ectopic expression of a peanut 9-cis-epoxycarotenoid dioxygenase gene. Biochemical and Biophysical Research Communications, v.347, p.1030-1038, 2006.

ZHAO, S.; RUSSEL, F. Comprehensive algorithm for quantitative real-time polymerase chain reaction. Journal of Computational Biology, v.12, p.1047-1064, 2005.

ZHENG, J.; ZHAO, J.; TAO, Y.; WANG, J.; LIU, J.; FU, J.; JIN, Y.; GAO, P.; ZHANG, J.; BAI, Y.; WANG, Y. Isolation and analysis of water stress induced genes in maize seedlings by subtractive PCR and cDNA macroarray. Plant Molecular Biology, v.55, p.807-823, 2004.

ZILLI, J.E.; VALICHESKI, R.R.; RUMJANEK, N.G.; SIMÕES-ARAÚJO, J.L.; FREIRE FILHO, F.R.; NEVES, M.C.P. Eficiência simbiótica de estirpes de Bradyrhizobium isoladas de solos do Cerrado em caupi. Pesquisa Agropecuária Brasileira, v.41, p.811-818, 2006.

Recebido em 28 de março de 2011 e aprovado em 30 de maio de 2012 